\title{
Implications of the Paris Climate Change Agreement for Adaptation Research and Universities
}

Edward Morgan, Willow Hallgren, Fernanda Helfer, Oz Sahin, Johanna Nalau, Esther Onyango, Wade Hadwen and Brendan Mackey

Edward A. Morgan, Willow Hallgren, Fernanda Helfer, Oz Sahin, Johanna Nalau, Esther Onyango, Wade Hadwen and Brendan Mackey

Griffith Climate Change Response Program, Gold Coast campus, Griffith University, Parklands Drive, Southport, Queensland 4222, Australia

Edward A. Morgan

Corresponding author: ed.morgan@griffith.edu.au

Willow Hallgren

w.hallgren@griffith.edu.au

Fernanda Helfer

f.helfer@griffith.edu.au

Oz Sahin

o.sahin@griffith.edu.au

Johanna Nalau

j.nalau@griffith.edu.au

Esther Onyango

e.onyango@griffith.edu.au

Wade Hadwen

w.hadwen@griffith.edu.au

Brendan Mackey

b.mackey@griffith.edu.au

\begin{abstract}
The recent Paris climate change agreement has resulted in a consensus between 196 countries on the need for action, including a stated aim to try to limit warming to $1.5{ }^{\circ} \mathrm{C}$. Despite its weaknesses, it will provide the policy basis for climate change action and research within signature countries. Scientific research is highlighted in the agreement as having a key role to play, and higher education institutions will be expected to lead the way in this research. Much of the focus will be on mitigation but the agreement places substantial emphasis on climate change adaptation. The purpose of this article is to discuss what the agreement might mean for climate change adaptation research, and how it might impact upon research agendas in higher education institutions. In considering how the agreement might impact upon different areas of adaptation research, the paper highlights how effective interdisciplinary collaboration and research is going
\end{abstract}


to be needed to support the lofty aims of the Paris agreement. It discusses the challenges of this research approach and how universities might be able to support the Paris agreement.

Keywords: climate change adaptation, interdisciplinary research, vulnerability, resilience

\section{Introduction}

The Paris Climate Change Agreement resulted in 196 countries agreed to limit atmospheric warming to $2{ }^{\circ} \mathrm{C}$ and to "pursue efforts" to limit warming to $1.5^{\circ} \mathrm{C}$ as compared with preindustrial times (i.e. before 1750). In addition, the parties agreed to "aim to reach global peaking of greenhouse gas emissions as soon as possible" (Article 4, point 1) and achieve net zero emissions in the second half of the $21^{\text {st }}$ Century. The Agreement was hailed as a success after pessimistic expectations prior to the meeting, but there remain significant questions over whether the aims can be achieved and achieved quickly and equitably (Clémençon, 2016).

The Agreement makes it clear that science and research are key to providing a robust basis for its implementation. Higher education institutions, and especially universities, are likely to be leaders and partners in developing the scientific understanding to inform responses to climate change. They have already played a key role in providing much of the research that is the basis of the IPCC Assessment Reports. This role is expected to be even stronger after the Paris Agreement.

Notably, the Paris Agreement elevates adaptation as a significant policy issue to be considered. Article 7 of the Agreement specifically addresses adaptation, and presents the possibility of a global adaptation goal (Magnan, 2016) and national level assessments of adaptation progress and reporting mechanisms. As an interdisciplinary climate change research team we were interested in the implications of this adaptation focus for universities and researchers. Here, we draw on our wide range of expertise in different aspects of adaptation to analyse the Paris agreement in the context of the current literature around adaptation. We use a qualitative document analysis combined with a synthesis of the current adaptation literature to assess the implications of the Agreement, and particularly the call for national adaptation assessments.

The purpose of this article is to discuss what might be needed from researchers and universities in light of the Paris Agreement and identify the challenges this research poses. It is also the intention of this study to suggest some key aspects of adaptation research for researchers and universities to focus on. First, we briefly discuss what is new for adaptation in the Paris Agreement and areas that are missing for adaptation, in order to provide key background context. This document analysis compares the Paris Agreement with previous agreements, and then compares what the Agreement says about adaptation in the context of existing literature. Then we discuss the implications for adaptation research, its links to decision-making in the implementation of the Paris Agreement commitments and the role of universities in supporting the commitments of the Agreement. This analysis draws on a review of the literature to compare 
the state-of-the-art for adaptation assessment with the needs implied by the Paris Agreement. It then places the results of the comparison into the context of the challenges and opportunities for universities. The analysis only focuses on one aspect of what an adaptation assessment might require - assessing vulnerability and adaptation options - as it is here that research has a vital role to play. Choosing options and monitoring them will follow from this, and research can have a role here too, but we do not discuss this here. Similarly, the analysis is not exhaustive - there are no doubt a range of other implications for universities and potential research priorities - the aim to highlight what we see as the key challenges and opportunities, based on the current state of adaptation research.

\section{Adaptation in the Paris Agreement}

In light of growing evidence of climatic changes that are irreversible (Solomon et al., 2009), adaptation has received increasing attention in policy, practice and research. Adaptation, however, has steadily gained more prominence and importance in UNFCCC agreements from Conferences of the Parties (COP), as climate change and the scope of necessary actions has become better understood. The Copenhagen Accord that emerged from COP15 in 2009 attracted substantial criticism for its failures on mitigation agreements (Rogelj \& Meinshausen, 2010; Rogelj et al., 2010) and included very little discussion of adaptation. In contrast, the following COP at Cancun (COP16, 2010) resulted in several agreements, one of which focused on adaptation. The Cancun Agreements stated that adaptation should be given the same priority as mitigation, and they established the Cancun Adaptation Framework, "with the objective of enhancing action on adaptation" (UNFCCC, 2010, point 13).

After the limited scope of COPs 17-20, COP21 in Paris became the focal point for a legally binding and universal agreement on climate. Although mitigation remains the focus of the Paris Agreement, adaptation goals are prioritised more than in previous agreements. The Agreement also expands the aims and goals for adaptation, begins to crystallise some of the elements of adaptation of previous agreements, and also encourages the development of a framework for adaptation assessment and reporting.

One of the successes of the Paris Agreement is a global adaptation goal (Article 7, point 1). Magnan (2015, p. 160) points out that the Agreement "aims to build a collective understanding of adaptation through metrics and tools that capture each country's efforts". The aim of a more collective understanding of and approach to adaptation, as well as the idea of collating and comparing the efforts of the Parties suggests a more ambitious and collaborative attitude towards adaptation. The Paris Agreement includes a call for National Adaptation Plans to be submitted to the UNFCCC, highlighting a shift towards greater action on adaptation. Similarly, the Parties agree to include the "state of adaptation efforts, support, experiences and priorities" (Decision 100, (a), (ii), page 14) into the global stocktake called for in the Agreement. However, the language around the adaptation communication is less definite than for mitigation reporting: 
"Each Party should, as appropriate, submit and update periodically an adaptation communication, which may include its priorities, implementation and support needs, plans and actions, without creating any additional burden for developing country Parties" (Article 7, point 10, emphasis added). It is also not clear how such a communication would be assessed.

The language used in the adaptation elements of the Paris Agreement does imply a growing consensus on how adaptation should be framed, discussed and implemented. For example, the terms "vulnerability, resilience and adaptive capacity" appear several times throughout the Agreement. These are key terms that are increasingly providing the conceptual basis for climate change adaptation research (e.g. Gallopín, 2006; Ford et al., 2015; Adger, 2006; Folke, 2006). The use of these terms, in addition to the focus on sharing information, strengthening institutions and scientific knowledge, and moving towards the assessment of adaptation, reflects efforts to create a more connected approach to adaptation within the UNFCCC. Hence, the Paris Agreement can be interpreted as a step towards crystallising adaptation as a concept, in order to support efforts towards implementing adaptation actions. However, the relationship between these three concepts is still somewhat unclear and the subject of debate and research (Gallopín, 2006). This is important because an adaptation approach focused on resilience might not be the same as an approach focused on vulnerability. For example, recent focus on social-ecological resilience emphasises the ability of systems to transform (Folke, 2006) and it is unclear how transformation might fit with vulnerability, which is more focused on sensitivity, exposure and capacity to respond (IPCC 2014a, 2014b).

The Paris Agreement also emphasises reporting and assessing adaptation efforts. It includes adaptation in the global stocktake and calls for adaptation communications. Further, there are calls for "assessment of climate change impacts and vulnerability" (Article 7, point 9c), "monitoring and evaluating and learning from adaptation plans, policies, programmes and actions" (Article 7, point 9d) and to "review the adequacy and effectiveness of adaptation and support provided for adaptation" (Article 7, point 14c). The inclusion of a section on climaterelated loss and damage (building from the Warsaw Agreement) would also appear to reflect moves towards assessing and monitoring adaptation at a global level. Assessing loss and damage remains a challenge (Huggel et al., 2013) but it does provide a mechanism for considering adaptation in terms of impacts of climate change and mitigation efforts (Huq et al., 2013; James et al., 2014).

There appears to be an effort within the Paris Agreement to place adaptation on a similar footing to mitigation in terms of global effort and cooperation. The Paris Agreement is well balanced between the two concepts, and the attempt to both clarify and encourage assessment of adaptation indicates a move towards a global approach to adaptation, just as there is for mitigation. However, whereas for mitigation, clear targets on emissions can be reported and assessed (as seen with the NDCs), measuring adaptation is far more complex, and the research 
into adaptation is less well developed (Tol, 2005; Füssel, 2007; IPCC 2014a). Monitoring and evaluation of adaptation is difficult because it deals with complex social-ecological processes that need to be considered over long time-frames and at a variety of different scales, and so viewpoints differ on success and failure (IPCC AR5 Chapter 14; Adger et al., 2009). The language of the Paris Agreement reflects this complexity and uncertainty and results in the adaptation text being much less definite than that for mitigation.

Hence, although adaptation receives significant attentions in the Paris Agreement, we argue that the language around it is less definite and clear than for mitigation. This likely reflects the complexity of adaptation and our less well-established understanding of adaptation, how to achieve it, and how to assess it. In this respect, the Paris Agreement highlights the challenges and the opportunities for adaptation research going forward, which is the focus of the next section.

\section{Adaptation Research to Support the Paris Agreement}

This section discusses the research challenges specifically related to climate change adaptation support policy and the Paris Agreement, and how universities can support adaptation research efforts.

The Paris Agreement suggests that there is an urgent need for the development of more concrete, politically and economically feasible adaptation policies to allow for National Adaptation Plans (NAP) to be submitted to and assessed by the Parties of the UNFCCC. This implies a requirement for more specific and detailed options for adaptation, that build upon more general adaptation measures that have been set in existing plans (e.g. the national climate change action plans developed by European and Latin American countries, see Metternicht et al., 2014). Currently, there are NAP guidelines to assist countries to undertake the steps and activities to facilitate 'country-owned, country-driven' medium and long-term adaptation to climate change (UNFCCC, 2015b). These guidelines are non-prescriptive and are designed to create an opportunity for countries to learn how to manage "multiple stress factors that combine in complex ways across scales" (Least Developed Countries Expert Group, 2012). The nature of these guidelines reflects the challenge of adaptation from both a research and policy perspective - the complexity of interrelated factors across different scales resulting in highly context-specific adaptation needs. Nonetheless, there is agreement that the first stages of adaptation need to be about identifying adaptation needs and options, and providing some assessment of these options (Least Developed Countries Expert Group, 2012; Hinkel et al., 2013).

We suggest that these steps necessitate an integrated Vulnerability, Impact and Adaptation (VIA) Assessment. VIA assessments would seek to provide a clear understanding of the causes, areas of vulnerability and actual impacts, based on site-specific knowledge and scientific data, as well as taking into account political, social and cultural processes that may facilitate or impede the implementation of the suggested adaptation measures (PROVIA, 2013; Bizikova et al., 2009). 
Here, we draw on the state of the art of the adaptation literature to discuss how adaptation research can help formulate 'best practice' VIA assessment to enhance the effectiveness of climate change adaptation, support the development of NAPs. The discussion highlights some of the challenges that need to be addressed and the role universities can play in supporting climate change adaptation.

\subsection{Interdisciplinary and Integrated Research}

Both adaptation research in general, and VIA assessments specifically, should be designed to be interdisciplinary and integrated. The first challenge for an effective VIA assessment is to do away with the traditional silo mentality, and to ensure such research projects are performed by a multidisciplinary team of technical experts (e.g., specialists in climate science, ecosystems and biodiversity, socio-economic scientists, experts in stakeholder engagement, policy development and communications), in order to incorporate biophysical, policy, socioeconomic and cultural perspectives. Calls for interdisciplinary and integrated research in climate change are not new, of course, and the difficulties are well documented (Adger, 2006; Adger et al., 2009; Thornton et al., 2014).

Uncertainty can be a particular challenge for such research. Uncertainty has been a major challenge for climate change research and policy (Dessai, 2007) and the challenge is greater for adaptation (Fussel, 2007). Hence, recognition and evaluation of uncertainties is essential. In an adaptive process, uncertainty analysis also enables the identification of which variables are uncertain and determinant in explaining vulnerability to climate change (Vignola et al., 2009). Uncertainty also needs to be communicated effectively, and researchers and policymakers will need to develop a shared understanding of the uncertainty to ensure that action is not delayed by calls for more research, and that failures are understood as part of the uncertain process.

Universities will need to support this interdisciplinary approach by allowing time and resources for collaboration and recognising that skills such as engagement and communication are currently not well-evaluated and often under-valued. Interdisciplinary research centres are becoming more common, but genuinely interdisciplinary research can still face institutional challenges.

\subsection{Scale and Context}

VIA assessment should be site-specific and conducted at the local scale. The challenge here is that many assessments show results on regional and global scales (e.g. Vörösmarty et al. 2010; Houghton \& English 2014; McIver et al., 2015), providing a broad view that seldom helps interested parties to design site specific local adaptation (Vignola et al., 2009). We suggest that VIA assessments should continue being undertaken at local level to produce more tangible adaptation initiatives. This comes with the policy challenge that NAPs are to be reported at a country scale, and thus an effective global-scale adaptation tracking is necessary. There are 
likely complex interactions between vulnerabilities, impacts and adaptations at the local and national scale. If the focus of VIA assessment is at the local scale, this mismatch needs to be addressed.

Similarly, tools and methods employed in the assessment should be tailored to the specific context in which the assessment outputs are to be applied. Outputs should be site-specific and applicable to the study area. The role of researchers includes the identification of the best tools and methods to use, given the scope of the VIA assessment. This underlines the challenge that adaptation research faces. Whereas mitigation reporting will tend towards generalizable, comparable methods, adaptation assessment seems to require the opposite (Fussel, 2007). This is a problem both for researchers - who are searching for general conclusions to report to the scientific community - and policymakers - who want to compare and contrast policies and actions to learn from them (or ideally transplant methods from one area to another). We suggest that adaptation research will increasingly need to learn from, compare and draw more general conclusions from context-specific adaptation.

Universities are well-placed to support research for the regions in which they are based. However, there is pressure to make research internationally relevant, or to make it of interest to the dominant US and European audience. Universities can balance this by recognising that local and regional outreach and collaboration will be vital to support adaptation research. They do of course face the pressure of needing to compete for research funding, and research funding bodies also need to recognise how local and context specific research is important.

\subsection{Stakeholder Engagement}

Stakeholders should be involved during the entire assessment process. Stakeholders can provide important contextual knowledge so researchers are able to understand local processes of adaptation and ecosystem management. The Paris Agreement notes the importance of a "genderresponsive, participatory and fully transparent approach", that considers vulnerable groups, communities and ecosystems", and is guided by "the best available science and, as appropriate, traditional knowledge, knowledge of indigenous peoples and local knowledge systems". In the first stages, for example, stakeholders will assist with the definition of the scope and determining the objectives of the assessment; in the final stages, they will validate and ensure the relevance and use of the final outputs. They will also help prioritise the adaptation options set in the assessment. The role of researchers should include finding methods for better stakeholder engagement in climate change adaptation assessments and to effectively communicate the results to them (Harrison et al., 2013; PROVIA, 2013). Importantly, this engagement has the potential to improve planning and policy as well (Cameron \& Grant-Smith, 2014; Collins \& Ison, 2009). However, engagement is no guarantee of success, and stakeholder engagement in both research and policy can be resource-intensive. 
Importantly, researchers will need to ensure that results are communicated in a way that is relevant to policymakers (Vignola et al., 2009). At the local and national levels, a participatory process should ideally take place in the policy design process, including problem identification, strategy formulation, selection of policy options, and monitoring and evaluation. At the global level, scientists can play an important advisory role to national policymakers who participate in international negotiations related to climate change adaptation. Such interactions are not without difficulties, however - adaptation and adaptation research can easily be politicised and used to justify actions taken from a purely political motive or to support a particular political agenda and maintain power structures (Eriksen et al., 2015). Similarly, policy processes can become overly scientific, ignoring the concerns and values of those impacted (whether by climate change or adaptation) (Lackey, 2007). Researchers will have to explore ways of interacting with policy to create shared understandings of the issue(s) at stake (Hoppe, 2013).

Researchers will need to find new ways of working with a wide range of stakeholders (Gardner et al., 2009; Harrison et al., 2013; PROVIA, 2013; IPCC 2014b), much in the same vein as they will be required to work with colleagues from different disciplines, and universities will need to support this. At the same time universities will need to support such engagement and value it, and provide training and support to develop the necessary skills. There is an increased focus on impact in assessing research in universities, which would seem to parallel this need for greater interaction with stakeholders and policy-makers. However, there are still concerns over how impact will be measured. A focus on impact within the scientific community or on short-term impact will not support greater engagement.

\subsection{Climate Change Communication}

A dialogue about climate change needs to continue between climate change scientists of all relevant disciplines, decision makers and the civil society. Scientists, or science research managers, will need to devote substantial efforts in communicating research results to nonscientists, such as local NGOs, public administration and the media, in order to increase their capacity to influence the implementation adaptation (Vignola et al., 2009). However, climate change remains a politically divisive topic. Although the Paris Agreement might have created a consensus on the need for action, translating that on the ground will be challenging where climate scepticism and conflicting political issues can stall progress. Universities can support these efforts by that they continue to support climate research, focus on outreach and provide training and support to researchers that try to get involved in these issues. Of course, key will be continuing to educate current and future students, teaching them to think about and understand the issue of climate change in all its complexity.

\subsection{Equity}

A final issue that must always be considered, and that cuts across all of the above, is that of equity. Research remains an Anglo-centric, Western-focused and male-dominated field, yet the 
impacts of climate change will be felt most heavily in the global south and among the poorest and most vulnerable communities (IPCC, 2014a). At the same time, adaptation must not be about protecting the wealth of those that have it at the expense of the poor. Researchers and universities have a responsibility to ensure those that cannot afford their own research are not left out, and that data, information and ideas are relevant, and available to all. Similarly, universities need to ensure that they challenge inequity and inequality within their institutions. This is as much a challenge for society as a whole as it is for research, but it must be part of the adaptation agenda at every level.

\section{Conclusion}

This article has discussed the adaptation aspects of the Paris Agreement, their implications for adaptation research and the role of universities in implementing the commitments of the Agreement. We argue that there is a clear attempt to place adaptation alongside mitigation in the Agreement, highlighting its growing importance as the climate changes. However, our analysis also demonstrates that adaptation remains complex and uncertain, and significant challenges remain if it is to become a part of mainstream policy and planning. To support this, we argue that adaptation research will need to (a) address the complexity and uncertainty of social-ecological systems, (b) be context-specific, (c) connect the local scale to national interests, and (d) be equitable and inclusive of stakeholders. Universities will have to support these efforts through training and recognition of aspects of research beyond simply academic novelty and impact. This may need them to challenge existing institutional barriers to the sort of research needed. No doubt this is a massive challenge, but we suggest that there are also opportunities for genuinely interdisciplinary, inclusive research to engage with stakeholders to help implement the Paris Agreement and support climate change adaptation. Just as the climate is changing and forcing societies to adapt, so are the expectations of what researchers and universities can provide in terms of knowledge and understanding. Researchers played a key role in putting climate change and the need for mitigation on the public agenda and, although that battle is still being fought, universities and researchers need to adapt their institutions to better support the adaptation needs highlighted in the Paris Agreement.

\section{Acknowledgements}

We acknowledge the support provided by the Griffith Climate Change Response Programme for this study. We also acknowledge the support provided by CNPq (Brazil) to Dr Fernanda Helfer, one of the authors of the paper. 


\section{References}

Adger, W. N. (2006). Vulnerability. Global Environmental Change, 16(3), 268-81.

Adger, W. N., Eakin, H., \& Winkels, A. (2009). Nested and teleconnected vulnerabilities to environmental change. Frontiers in Ecology and the Environment, 7(3), 150-157.

Bizikova, L., Bellali, J., Habtezion, Z., Diakhite, M., \& Pinter, L. (2009), IEA Training Module Volume 2 - Vulnerability and Impact Assessments for Adaptation to Climate Change. Nairobi: United Nations Environment Programme, 59 p.

Cameron, J., \& Grant-Smith, D. (2014). Putting people in planning: participatory planning, inclusion and power. In J. Byrne, J. Dodson, \& N. Sipe (Eds.), Australian Environmental Planning: Challenges and Future Prospects (pp. 197-205). London: Routledge.

Clémençon, R. (2016). The Two Sides of the Paris Climate Agreement: Dismal Failure or Historic Breakthrough. Journal of Environment and Development, 25(1), 3-24.

Collins, K., \& Ison, R. (2009). Jumping off Arnstein's ladder: social learning as a new policy paradigm for climate change adaptation. Environmental Policy and Governance, 19(6), 358-373.

Dessai, S., O’Brien, K., \& Hulme, M. (2007). Editorial: On uncertainty and climate change. Global Environmental Change, 17(1), 1-3.

Eriksen, S. H., Nightingale, A. J., \& Eakin, H. (2015). Reframing adaptation: The political nature of climate change adaptation. Global Environmental Change, 35, 523-533.

Folke, C. (2006). Resilience: The emergence of a perspective for social-ecological systems analyses. Global Environmental Change, 16(3), 253-267.

Ford, J. D., Berrang-Ford, L., Biesbroek, R., Araos, M., Austin, S. E., \& Lesnikowski, A. (2015). Adaptation tracking for a post-2015 climate agreement. Nature Climate Change, 5(11), 967-969.

Füssel, H. M. (2007). Adaptation planning for climate change: Concepts, assessment approaches, and key lessons. Sustainability Science, 2(2), 265-275.

Gallopín, G. C. (2006). Linkages between vulnerability, resilience, and adaptive capacity. Global Environmental Change, 16(3), 293-303.

Gardner, J., Dowd, A-M., Mason, C. \& Ashworth, P. ( 2009). A Framework for Stakeholder Engagement on Climate Adaptation. CSIRO Climate Adaptation Flagship Working Paper 3. Kenmore: CSIRO, $32 \mathrm{p}$.

Harrison, P., Holman, I.P., Cojocaru, G., Kok, K., Kontogianni, A., Metzger, M.J., \& Gramberger, M.( 2013). Combining Qualitative and Quantitative Understanding for Exploring Cross-Sectoral Climate Change Impacts, Adaptation and Vulnerability in Europe. Regional Environmental Change, 13(4), 761-80.

Hinkel, J., Bharwani, S., Bisaro, A., Carter, T., Cull, T., Davis, M., Klein, R., Lonsdale,K., Rosentrater, L., \& Vincent K., (2013) PROVIA Guidance on Assessing Vulnerability, Impacts and Adaptation to Climate Change - SUMMARY. Nairobi: United Nations Environment Programme, 20 p. 
Hoppe, R., Wesselink, A., \& Cairns, R. (2013). Lost in the problem: The role of boundary organisations in the governance of climate change. Wiley Interdisciplinary Reviews: Climate Change, 4(4), 283-300.

Houghton, A. \& English, P. (2014). An Approach to Developing Local Climate Change Environmental Public Health Indicators, Vulnerability Assessments, and Projections of Future Impacts. Journal of Environmental and Public Health, 132057.

Huggel, C., Stone, D., Auffhammer, M., \& Hansen, G. (2013). Loss and damage attribution. Nature Climate Change, 3(8), 694-696.

Hulme, M. (2016). $1.5^{\circ} \mathrm{C}$ and climate research after the Paris Agreement. Nature Climate Change, 6(3), 222-224.

Huq, S., Roberts, E., \& Fenton, A. (2013). Loss and damage. Nature Climate Change, 3(11), 947-949.

IPCC (2014a). Climate Change 2014: Impacts, Adaptation, and Vulnerability. Part A: Global and Sectoral Aspects. Contribution of Working Group II to the Fifth Assessment Report of the Intergovernmental Panel on Climate Change. Cambridge: Cambridge University Press, $1132 \mathrm{p}$.

IPCC (2014b). Climate Change 2014: Impacts, Adaptation, and Vulnerability. Part B: Regional Aspects. Contribution of Working Group II to the Fifth Assessment Report of the Intergovernmental Panel on Climate Change. Cambridge: Cambridge University Press, 688 p.

James, R., Otto, F., Parker, H., Boyd, E., Cornforth, R., Mitchell, D., \& Allen, M. (2014). Characterizing loss and damage from climate change. Nature Climate Change, 4(11), 938939.

Least Developed Countries Expert Group (2012). National Adaptation Plans. Technical guidelines for the national adaptation plan process. Bonn: United Nations Climate Change Secretariat, $152 \mathrm{p}$.

Lackey, R. T. (2007). Science, scientists, and policy advocacy. Conservation Biology: The Journal of the Society for Conservation Biology, 21(1), 12-17.

Magnan, A. K. (2016). Climate change: Metrics needed to track adaptation. Nature, 530(7589), 160.

Metternicht, G., Sabelli, A., and Spensley, J. (2014) Climate Change Vulnerability, Impact and Adaptation Assessment: lessons from Latin America. International Journal of Climate Change Strategies and Management, 6(4), 442-476

McIver L., Kim R., Woodward A., Hales S., Spickett J., Katscherian D., Hashizume M., Honda Y., Kim H., Iddings S., Naicker J., Bambrick H., McMichael A.J., Ebi K.L. (2015). Health Impacts of Climate Change in Pacific Island Countries: A Regional Assessment of Vulnerabilities and Adaptation Priorities. Environmental Health Perspectives, 1509756.

PROVIA (2013). PROVIA Guidance on Assessing Vulnerability, Impacts and Adaptation to Climate Change. Nairobi: United Nations Environment Programme, 174 p. 
Rogelj, J., \& Meinshausen, M. (2010). Copenhagen accord pledges are paltry. Nature, 464(7292), 1126-1128.

Rogelj, J., Chen, C., Nabel, J., Macey, K., Hare, W., Schaeffer, M., Markmann, K., Hohne, N., Andersen, K.K., \& Meinshausen, M. (2010). Analysis of the Copenhagen Accord pledges and its global climatic impacts-a snapshot of dissonant ambitions". Environmental Research Letters, 5(3), 034013.

Solomon, S., Plattner, G.-K., Knutti, R., \& Friedlingstein, P. (2009). Irreversible climate change due to carbon dioxide emissions. Proceedings of the National Academy of Sciences of the United States of America, 106(6), 1704-1709.

Thornton, P. K., Ericksen, P.J., Herrero, M., \& Challinor, A.J. (2014). Climate Variability and Vulnerability to Climate Change: A Review. Global Change Biology, March, 1-16.

Tol, R. (2005). Adaptation and mitigation: trade-offs in substance and methods. Environmental Science \& Policy, 8(6), 572-578.

UNFCCC (2010). Cancun Agreement to the United Nations Framework Convention on Climate Change, II, 13. Dec. 11. Available from: http://unfccc.int/resource/docs/2010/cop16/eng/07a01.pdf\#page $=4$

UNFCCC (2014). National Adaptation Programmes of Action (NAPAs). Retrieved April 13, 2016, from http://unfccc.int/national_reports/napa/items/2719.php.

UNFCCC (2015a). Enhancing Coherent Action on Adaptation 2012-2015. Bonn: United Nations Climate Change Secretariat, $32 \mathrm{p}$.

UNFCCC (2015b). Navigating the Landscape of Support for the Process to Formulate and Implement National Adaptation Plans. Bonn: United Nations Climate Change Secretariat, $48 \mathrm{p}$.

UNFCCC (2015c). Synthesis report on the aggregate effect of INDCs. Paris: United Nations, 66 p.

Vignola, R., Locatelli, B., Martinez, C., \& Imbach, P. (2009). Ecosystem-based adaptation to climate change: What role for policy-makers, society and scientists? Mitigation and Adaptation Strategies for Global Change, 14 (8), 691-696.

Vörösmarty, C. J., McIntyre P. B., Gessner, M. O., Dudgeon, D., Prusevich, A., Green, P. A., Glidden, S., Bunn, S. E., Sullivan, C. A., Reidy, C. A., \& Davies, P. M. (2010). Global threats to human water security and river biodiversity. Nature, 467, 555-561. 